\title{
Pro-health behaviours - a sense of coherence as the key to a healthy lifestyle in rural areas?
}

\author{
Monika Binkowska-Bury' ${ }^{1}$, Grazyna Iwanowicz-Palus², Wacław Kruk', Lidia Perenc ${ }^{3}$, Artur Mazur ${ }^{3}$, \\ Rafał Filip ${ }^{3}$, Paweł Januszewicz ${ }^{3}$ \\ ${ }^{1}$ Institute of Nursing and Health Sciences, Medical Department, University of Rzeszow, Poland \\ 2 Independent Practical Obstetric Skills Unit, Medical University, Lublin, Poland \\ ${ }^{3}$ Medical Faculty, University of Rzeszow, Rzeszow, Poland
}

Binkowska-Bury M, Iwanowicz-Palus G, Kruk W, Perenc L, Mazur A, Filip R, Januszewicz P. Pro-health behaviours - a sense of coherence as the key to a healthy lifestyle in rural areas? Ann Agric Environ Med. 2016; 23(2): 345-349. doi: 10.5604/12321966.1203903

\begin{abstract}
Ibstract
Background. Health-related behaviours and lifestyle are related to the salutogenic concept of health, whereas the major public health problems faced in rural areas include difficulties in encouraging people to a healthy lifestyle.

Objective. The aim of the study is to explore mutual relationships between psychosocial-demographic factors and a sense of coherence.

Material and method. Two-stage sampling was applied. Data were collected with the use of the Juczynski Health Behaviours Inventory and Antonovsky's SOC-29 (Sense of Coherence Questionnaire). The study was conducted among 668 adults. Data were statistically prepared using one-way ANOVA test, linear correlation analysis, and linear regression model.

Results. A higher level of pro-health behaviours is associated with gender, self-rated health, sense of coherence and age. Almost half of the farmers were characterized by a low level of pro-health attitudes. A higher level of pro-health behaviours was demonstrated by less than one-fifth of the farmers.

Conclusions. There is a strong association between sense of coherence and pro-health behaviours. Farmers have bad habits and pro-health attitudes to health and poorer self-assessment of their health. There is a great need to monitor health-related behaviour, increase the effectiveness of health promotion and health education in shaping a pro-health lifestyle among residents of rural areas, particularly among farmers.
\end{abstract}

\section{Key words}

lifestyle, psycho-social-demographic features, sense of coherence, farmers

\section{INTRODUCTION}

Researches on the health of rural residents focus primarily on health care needs and access issues, rather than perceptions and values of health. Indeed, strong disparities in access to health care services between urban and rural areas are present worldwide $[1,2]$. The inhabitants of rural regions, on average, live much further from a major hospital than those of urban regions, and basic health care services are generally harder to provide. The same situation is observed in the USA and Australia where rural residents have a limited access to health care services and fewer visits to doctors than their urban counterparts [2]. As a result, the great majority are deprived of professional health care, including prophylaxis and health promotion.

Numerous worldwide studies indicate that the major public health problems faced in rural areas include difficulties in encouraging people to a healthy lifestyle $[3,4,5]$. As indicated by previous researches, rural residents smoke more, drink more alcohol, exercise less, have less nutritional diets, and are more likely to be obese than urban residents $[6,7,8]$. Together, these studies suggest that risk behaviorus rather than prohealth are more common among rural area residents.

Address to correspondence: Monika Binkowska-Bury, Institute of Nursing and Health Sciences, Medical Department, University of Rzeszow, Rejtana 16C 35-328 Rzeszów, Poland

e-mail: monika.binkowska@yahoo.com

Received: 11 March 2013; accepted: 28 May 2014
Healthy behaviours are the result of an attitude to health, acquired during our whole life. As indicated by previous researches, health-related behaviours and lifestyle are related to the salutogenic concept of health. According to Aaron Antonovsky, each person has an individual predisposition, which makes that person more or less resistant to stressful factors when confronting everyday life. This intriguing theory significantly broadened the understanding of the mutual relations between health and the causes of some diseases. It was Antonovsky's great contribution to precisely identify those predispositions, determined by him as a sense of coherence (SOC) which guarantees efficient methods of coping with stress and having a positive influence on healthrelated behaviour $[9,10]$. Research dedicated to a sense of coherence and its impact on human's health was carried out not long ago and is the current subject of many studies. Some correlations between SOC and healthy behaviours have been identified in the literature $[11,12,13]$. Previous studies demonstrate that while people with a strong SOC are shown to be associated with healthy life style choices and habits, those with weak SOC may have been engaged in less healthy behaviour, such as smoking, because they were less able to deal with every day distress [14]. People with a high SOC engage in regular dental health practices, brushing their teeth twice or more times a day, having non-smoking habits and lower intake of sucrose and sweets [15].

The aim of the study is to explore mutual relationships between psychosocial-demographic factors and a sense of coherence. 


\section{MATERIAL AND METHODS}

The study was conducted between January - September 2010 in the Podkarpackie Province of south-eastern Poland. This region is inhabited by $2,170,000$ people and is characterised by the highest rate of rural areas inhabitants in Poland (59.6\%). Polish rural areas are specific due to the fact that most of inhabitants only live there, but work in urban areas. In fact, most of them spend their lives in urban areas and eventually adopt urban influences and lifestyle, as well as patterns of behaviours. Therefore, it was decided to excluded such people from the study, and take into consideration only those inhabitants of rural areas for whom the farm was the basic source of income (105.356 people based on data from the Farmers' Social Security Fund (KRUS) dated 31.12.2009) [16]. According to the principles specified in the Act, the Argicultural Social Insurance concerns farmers and members of the household who work with them.

Two-stage sampling was applied. The first sampling included 30 rural communes from a total of 110 communes in the Podkarpackie Province. The second-stage sampling included 10 households from selected communes. In total, the study population comprised 800 people who were inhabitants of rural areas of the Podkarpackie Province and work on farm as the basic source of income.

750 subjects agreed to participate, and eventually 668 were interviewed: 68 subjects were not interviewed because of incorrectly filled out questionnaires. The study sample was big enough to have an inconsiderable influence on estimation error. The collected results might be used with quite high accuracy for inferring to the whole population, as the statistical error values were approximately $\pm 3.8 \%$.

The questionnaires were filled out anonymously by the participants. Polsters Questionnaires were handed out by specially trained pollsters - nurses and public health students. Respondents were given oral and written instructions about the aim of the study and how to complete the questionnaire.

Patterns of health behaviour were assessed using two validated tools: Juczyński Health Behaviours Inventory (IZZ) and Antonovsky's SOC-29 (Sense of Coherence Questionnaire). In addition, an initial questionnaire obtained basic demographic data on participants age, gender, family status, education, place of residence, self-rated health and material status.

Juczynski Health Behaviours Inventory (IZZ) was created by Zygfryd Juczynski in 1997 and includes 24 statements describing different behaviours related to health. All items are rated on a 5-point scale: ' 1 - Almost never', '2 - Seldom', '3 From time to time', ' 4 - Often', ' 5 - Almost Always'. Taking into consideration the frequency of individual behaviours on a five-point scale indicated by the respondents, it is estimated that the general intensity of health-related behaviour and the intensities of four categories of pro-health behaviours: proper nutrition habits (type of foods, well-balanced diet); prophylaxis (health recommendations, health and disease information); positive attitude (psychological factors, such as avoiding too strong emotions, stress, anxiety, and depressive situations); and pro-health practices (sleep habits, recreation, and physical activity). Marked values are counted. The general value of pro-health behaviour indicators range from $24-120$ points: the higher the score, the higher the level of prohealth behaviours. A general indicator after transformation into standard units is interpreted with the use of standard ten. Results ranges of pro-health behaviours in standard ten are taken as follows: ' 1 - 4: Low level', ' 5 - 6: Average level', '7 - 10: High level'. This constitutes approximately $33 \%$ for both the lowest and the highest results. In addition, the intensity of four categories of pro-health behaviours is calculated separately. The Inventory of Health-Related Behaviour used with other types of diagnostic surveys may be helpful in planning prophylaxis activities, determining the direction of behaviours modification, and monitoring changes in health practices. An inventory may be used to examine both healthy and sick adults. The research results impart knowledge related to the present behaviour of the group examined, and may serve as an action programme promoting health and prophylaxis [17].

The level of sense of coherence was measured with the use of Antonovsky's SOC-29 [18]. In the presented study, the sense of coherence among the studied group was measured with the use of the Polish version of Antonovsky's SOC -29, prepared in accordance with methodological recommendations and translated both ways by psychologists-researchers, and authorized by Antonovsky. The scale was created in 1993 with the cooperation of three research centres conducting studies on SOC: Institute of Clinical Psychology (IPN), Institute of Psychology, Department of Psycho-prophylaxis (UAM), Institute of Labour Medicine, Department of Labour Psychology in Lodz [18].

Results from questionnaires were analyzed using statistical package STATISTICA 9.0 (Statsoft). Data were statistically prepared using one-way ANOVA, linear correlation analysis, and a linear regression model. A regression model was used in order to examine which factors significantly modify the level of pro-health behaviours. The following features (categorical) were implemented into the General Linear Model: gender, family status, education, place of residence, self-rate health, material status (net income), as well as a quantitative feature - level of sense of coherence (SOC). In the present model, interactions between features was not included.

The Commission for Bioethics at the General Medical Council in Rzeszow approved this study, which was conducted in accordance with the Helsinki Declaration. The study was financed by an individual grant for research projects according to Directive No. 100/2009 of the University of Rzeszow.

\section{RESULTS}

Among the 668 participants the majority were women (53.3\%). More than half of the study respondents (63\%) were covered by the Agricultural Social Insurance fund. The rest of the respondents (36.5\%) were spouses or household members who worked on the farm and were covered by the farmers' insurance (KRUS). The age ranges of respondents participating in this study were as follows: $<30$ years old (20.7\%); 31-40 (25.1\%); 41-50 (28.3\%); 51-60 (18.1\%), >60 (7.5\%). Two respondents did not give their age. The majority of respondents (41.2\%) had secondary education, $28.9 \%$ vocational education, $12.6 \%$ a bachelor's degree, $9.1 \%$ primary education, and $8.1 \%$ a master's degree. One respondent did not answer. The marital status of respondents was as follows: $71.7 \%$ married, $19.9 \%$ single, $6 \%$ widows or widowers and $1.3 \%$ divorced. One respondent did not answer. More than a half of the respondents (56.4\%) lived in villages and the rest 
Table 1. Characteristics of participants

\begin{tabular}{|c|c|c|}
\hline \multirow{2}{*}{ Participant Characteristics } & \multicolumn{2}{|c|}{ Total $(\mathrm{N}=668)$} \\
\hline & $\mathrm{N}$ & $\%$ \\
\hline \multicolumn{3}{|l|}{ Gender } \\
\hline Female & 356 & (53.3) \\
\hline Male & 307 & (46.0) \\
\hline No answer & 5 & (0.7) \\
\hline \multicolumn{3}{|l|}{ Agricultural Social Insurance Fund (KRUS) } \\
\hline Farmers & 421 & (63.0) \\
\hline Spouses / household members & 244 & (36.6) \\
\hline No answer & 3 & (0.4) \\
\hline \multicolumn{3}{|l|}{ Age (years) } \\
\hline$<30$ & 138 & (20.7) \\
\hline $31-40$ & 168 & (25.1) \\
\hline $41-50$ & 189 & (28.3) \\
\hline $51-60$ & 121 & (18.1) \\
\hline$>60$ & 50 & (7.5) \\
\hline No answer & 2 & $(0.3)$ \\
\hline \multicolumn{3}{|l|}{ Education } \\
\hline Primary & 61 & (9.1) \\
\hline Secondary & 193 & $(28.9)$ \\
\hline Vocational & 275 & $(41.2)$ \\
\hline Bachelor's degree & 84 & (12.6) \\
\hline Master's degree & 54 & (8.1) \\
\hline No answer & 1 & $(0.1)$ \\
\hline \multicolumn{3}{|l|}{ Marital status } \\
\hline Single & 133 & (19.9) \\
\hline Married & 479 & (71.7) \\
\hline Widow / widower & 40 & (6.0) \\
\hline Divorced & 9 & (1.3) \\
\hline No answer & 7 & (1.0) \\
\hline \multicolumn{3}{|l|}{ Place of residence } \\
\hline Villages & 377 & (56.4) \\
\hline Communes & 289 & (43.3) \\
\hline No answer & 2 & $(0.3)$ \\
\hline \multicolumn{3}{|l|}{ Farming area } \\
\hline $1-2$ ha & 308 & (46.1) \\
\hline 3-5 ha & 215 & (32.2) \\
\hline 6-10 ha & 96 & $(14.4)$ \\
\hline$<10$ ha & 39 & (5.8) \\
\hline No answer & 10 & (1.5) \\
\hline \multicolumn{3}{|l|}{ Net monthly income } \\
\hline$>125$ EUR & 293 & (43.9) \\
\hline 125-250 EUR & 291 & (43.6) \\
\hline 251-375 EUR & 63 & (9.4) \\
\hline$<375$ EUR & 18 & (2.7) \\
\hline No answer & 3 & (0.4) \\
\hline \multicolumn{3}{|l|}{ Source of income } \\
\hline Additional source of income besides farm & 445 & (66.6) \\
\hline Farm as only source of income & 91 & (13.6) \\
\hline Farm as main source of income & 122 & (18.3) \\
\hline No answer & 10 & (1.5) \\
\hline \multicolumn{3}{|l|}{ Self-rated health } \\
\hline Good & 194 & $(29.0)$ \\
\hline Quite good & 243 & (36.4) \\
\hline Neither good nor bad & 200 & (29.9) \\
\hline Rather bad & 23 & (3.4) \\
\hline Bad & 3 & (0.4) \\
\hline No answer & 5 & (0.7) \\
\hline
\end{tabular}

(43.3\%) in communes, and $0.3 \%$ did not answer. The self-rated health of participants was as follows: good (29\%), quite good (36.4\%), neither good nor bad (29.9\%), rather bad (3.4\%) and bad ( $0.4 \%) .0 .7 \%$ of respondents did not answer. The range of farming area (in round figures) owned by farmers was as follows: $1-2$ ha (46.1\%), 3-5 ha (32.1\%); 6-10 ha (14.4\%), $<10$ ha (5.8\%). 1.5\% did not answer the question. The range of net monthly income was as follows: > 125 EUR (43.9\%); 125-250 EUR (43.6\%); 251-375 EUR (9.4\%), <375 EUR (2.7\%). $0.4 \%$ of respondents did not answer. The source of income was the following: $66.6 \%$ additional source of income beside the farm, $18.3 \%$ farm as the only source of income, $13.6 \%$ farm as the main source of income. $1.5 \%$ of respondents did not answer.

Analysis of the results showed that almost a half of the studied sample (45\%) was characterised by a low level of pro-health behaviours, followed by an average level (37.3\%), and high level (17.7\%). Data proved that participants with a high level of pro-health behaviours more often placed greater stress on diet, avoided salt, animal fat, sugar and food containing preservatives. Instead, they eat more vegetables, fruit and wholegrain bread, and as well as controlling their body-weight, follow health recommendations related to their own health and disease, attempt to avoid strong emotions, stress, anger, fear and depressing situations, and they all lead balanced family lives and see their doctor regularly. Data demonstrated that women are characterized by a slightly greater intensity of pro-health behaviours than men $(\mathrm{p}=.000)$ (Tab. 1).

Evidences from this study showed that both respondents with good self-rated health $(\bar{x}=80.9 ; \mathrm{s}=12.3)$ and bad selfrated health $(\bar{x}=79.2 ; \mathrm{s}=12.3)$, were characterized by a greater intensity of pro-health behaviours ( $\mathrm{p}=.000)$ (Tab. 2).

Table 2. Gender and level of pro-health behaviours among farmers

\begin{tabular}{|c|c|c|c|c|}
\hline \multicolumn{4}{|c|}{ IZZ (points) \& Gender } & \multirow{3}{*}{$\begin{array}{c}p \\
T \text {-test }\end{array}$} \\
\hline \multicolumn{2}{|c|}{ Females $(\mathrm{N}=356)$} & \multicolumn{2}{|c|}{ Males $(\mathrm{N}=307)$} & \\
\hline $\bar{x}$ & s & $\bar{x}$ & $S$ & \\
\hline 79.4 & 15 & 71.9 & 13 & $.000^{* * *}$ \\
\hline
\end{tabular}

The obtained data considering sense of coherence showed a mean value of SOC valued 128.1 the standard deviation 19. The mean values of sense of coherence components were as follows: the sense of comprehensibility $(\bar{x}=44.9$; $\mathrm{s}=8,6)$; sense of manageability $(\bar{x}=44,8 ; \mathrm{s}=7,7)$; and sense of meaningfulness $(\bar{x}=38,3 ; s=6.6)$. There was a statistical dependency between sense of coherence and intensity of prohealth behaviours among farmers (total value 0.22) (Tab. 3).

Table 3. Self-rate health and level of intensity of pro-health behaviours

\begin{tabular}{|c|c|c|c|c|c|c|c|c|}
\hline \multicolumn{8}{|c|}{ IZZ (points) \& Self-rate health } & \multirow{3}{*}{$\begin{array}{c}\mathrm{p} \\
\text { ANOVA } \\
\text { test }\end{array}$} \\
\hline \multicolumn{2}{|c|}{$\operatorname{good}(N=194)$} & \multicolumn{2}{|c|}{$\begin{array}{l}\text { quite good } \\
(\mathrm{N}=243)\end{array}$} & \multicolumn{2}{|c|}{$\begin{array}{c}\text { neither good } \\
\text { nor bad } \\
(N=200)\end{array}$} & \multicolumn{2}{|c|}{$\operatorname{bad}(N=26)$} & \\
\hline $\bar{x}$ & $s$ & $\bar{x}$ & $s$ & $\bar{x}$ & $s$ & $\bar{x}$ & $s$ & \\
\hline 80.9 & 12.3 & 74.6 & 15.1 & 72.9 & 14.9 & 79.2 & 12.3 & $.000^{* * *}$ \\
\hline
\end{tabular}

Stepwise regression was used to search for an optimal model. Statistically significant effects are presented in Table 4. Data analysis demonstrated that the most important factors modifying the intensity of pro-health behaviours in the 
Table 4. Sense of coherence and intensity of pro-health behaviours (linear correlation coefficient)

\begin{tabular}{lccccc}
\hline $\begin{array}{l}\text { Components } \\
\text { of sense of } \\
\text { coherence }\end{array}$ & $\begin{array}{c}\text { Proper eating } \\
\text { habits }\end{array}$ & $\begin{array}{c}\text { Prophylactic } \\
\text { behaviour }\end{array}$ & $\begin{array}{c}\text { Positive } \\
\text { attitudes }\end{array}$ & $\begin{array}{c}\text { Health } \\
\text { practices }\end{array}$ & Total \\
\hline Comprehensibility & $0.09^{*}$ & $0.10^{* *}$ & $0.22^{* * *}$ & $0.12^{* *}$ & $0.16^{* * *}$ \\
\hline Manageability & $0.12^{* *}$ & $0.14^{* * *}$ & $0.26^{* * *}$ & $0.18^{* * *}$ & $\mathbf{0 . 2 1 ^ { * * * }}$ \\
\hline Meaningfulness & $0.13^{* * *}$ & $0.15^{* * *}$ & $0.25^{* * *}$ & $0.09^{*}$ & $\mathbf{0 . 1 8 ^ { * * * * }}$ \\
\hline Total & $0.14^{* * *}$ & $0.16^{* * *}$ & $0.30^{* * *}$ & $0.16^{* * *}$ & $0.22^{* * *}$ \\
\hline
\end{tabular}

regression model were as follows: gender $(p=.000)$, self-rated health $(p=.000)$, and age $(p=.016)$.

It was showed that there is a statistical difference between women and men in the intensity of pro-health behaviours, an average difference value of 8.5 points, which means that women had a higher level of pro-health behaviours (4.25) than men $(-4.25)$.

The differences between self-rated health and pro-health behaviours were also reported. People with good self-rated health had a higher level of pro-health behavious of about $5-6.5$ points (3.51) than those with quite good (-1.43) and an average self-rated health $(-2.89)$. There were also differences between age and pro-health behaviours. People $<60$ - yearsold had higher levels of pro-health behaviours of about 6-8.5 points than people of other ages (Tab. 5).

Table 5. Factors significantly modifying intensity of pro-health behaviours - IZZ (stepwise regression coefficient)

\begin{tabular}{|c|c|c|c|}
\hline Factor & Level of factor & $\begin{array}{l}\text { Coefficient in } \\
\text { regression model }\end{array}$ & $\mathrm{p}$ \\
\hline \multirow{2}{*}{ Gender } & Female & 4.25 & \multirow{2}{*}{$.000^{* * *}$} \\
\hline & male & -4.25 & \\
\hline \multirow{4}{*}{ Self-rated health } & good & 3.51 & \multirow{4}{*}{$.000^{* * *}$} \\
\hline & quite good & -1.43 & \\
\hline & neither good nor bad & -2.89 & \\
\hline & rather bad & 0.81 & \\
\hline \multirow{5}{*}{ Age } & $>30$ yrs & -0.95 & \multirow{5}{*}{$.016^{*}$} \\
\hline & $31-40$ yrs & -2.39 & \\
\hline & $41-50$ yrs & -1.10 & \\
\hline & $51-60$ yrs & -0.97 & \\
\hline & $>60 \mathrm{yrs}$ & 5.40 & \\
\hline Coherence & +1 point & 0.18 & $.000^{* * *}$ \\
\hline
\end{tabular}

It was seen that all effects included in the regression model explain only $20.5 \%$ of IZZ scale's variability; however, this is not a bad result when one considers how diversified individual attitudes are toward one's health.

\section{DISCUSSION}

The presented study has an innovative character and adds a new insight to the classical observation on public, directly bonding the level of sense of coherence with pro-health behaviours among farmers. It also underlines the significant role of that factor in undertaking health-related behaviours beyond the typical socio-demographic factors. However, in the available literature, missing data makes it difficult to conduct a comparative analysis with other scientists, an attempt was made to find analogies or similarities between published studies.

Based on the literature, it is worth underlining that place of residence significantly differentiates the level of pro-health behaviours $[4,5,19,20]$. Studies including the residents of rural areas show that improper health behaviour was characteristic for a large group of them. Among Polish rural residents, every fourth person smokes (24\%) every day, whereas in urban residents the value are $32 \%$ in towns and $33 \%$ in big cities. In comparison, in the USA, the majority of smokers are residents of rural areas $(33 \%)$ rather than urban residents (27\%) [19]. In addition, in recent years the consumption of alcohol in rural areas has increased worldwide [5].

Previous studies also show that people from rural areas have the worst eating habits, feel relatively more symptoms of stress, and subjectively negatively assess their quality of life in comparison with urban residents $[20,22]$. The results of the presented study are similar to the results of other authors. Almost half of the farmers were characterised by a low level of pro-health behaviour (45\%).

In the current study, it was found that from among the socio-demographic factors the most essential element of influence in shaping health was gender, which significantly differentiated the level of pro-health behaviours: women demonstrated a higher level of health-related behaviours. These findings are similar to other studies. Women more often take up prophylaxis check-ups, seek specialist advice more often, smoke less tobacco and consume less alcohol $[19,21,23]$.

Farmers who perceive their state of health as good more often undertook pro-health behaviours. It is worth indicating that in the final regression model, self-rated health was a strong predicator of pro-health behaviours, and also constituted an important psychical and physical efficiency. The current study is similar with regard to the self-rated health assessments of adult Polish residents, as shown in the Government Population Council Report on the demographic situation in Poland [21].

Finally, in the presented study it was found that the sense of coherence modified the intensity of pro-health behaviour. Such a factor decides to what degree the possessed resources (features of physical, social environment, including biological, material and social status) strengthens health and coping with stress. The level of sense of coherence has an influence if the person is healthy. In the study conducted among adult lay people, published in the world's literature, different results were obtained for sense of coherence $[24,25]$.

Similar results to those reported in our SOC study - 124.3, were obtained by Lam (2007) who studied 122 American students of Vietnamese origin. Japanese physicians obtained higher SOC values of $134.5[24,25]$. Those data indicate a significant differentiation in the level of SOC, which is consistent with Antonovsky's concept, according to which SOC is shaped, reinforced and refined throughout one's life, and a significant meaning is attributed to the conditions in which the child grows up and develops as a young person. The essential role of the influence of socio-cultural context (over a long period of time) and the pattern of life experience are shown to be very important in the establishment of sense of coherence.

The majority of studies conducted worldwide focus on the relationship between a high SOC and a state of good health 
[9]. According to Antonovsky, a strong sense of coherence favours a more frequent tendency towards pro-health behaviour and strengthening health [9].

International research conducted among youths and adults demonstrate a relationship between SOC and lifestyle [14, 15]. A study carried out by Wainwright et al. (2007) among 18,287 adult residents of the United Kingdom showed that people with a strong sense of coherence smoke less, undertake physical activity more often, and consume more fruit and vegetables [14]. An exception was the fact that people with a strong sense of coherence consume more alcohol.

Those relationships were not related to age, gender, social status and education. In the presented study it was found that individual SOC differences were related with the choice of pro-health behaviour, despite social status and education, and those with a higher sense of coherence smoked less. The results obtained by Lindmark et al. conducted among adult Swedish people showed that the sense of coherence is related to pro-health behaviours in relation to saturated fats, fibre, and alcohol [15].

There is a strong association between sense of coherence and pro-health behaviours. Gender, self-rated health, sense of coherence and age were factors differentiating the level of pro-health behaviours. Farmers have bad habits and prohealth attitudes to health and poorer self-assessment of their health. The results of the current study suggest that there is a great need to monitor health-related behaviour, increase the effectiveness of health promotion and health education in shaping a pro-health lifestyle among residents of rural areas, and particularly among farmers.

\section{REFERENCES}

1. Dixon J, Welch N. Researching the rural-metropolitan health differential using the 'social determinants of health'. Aust J Rural Health. 2000; 8: 254-260.

2. Bushy, A. Critical access hospitals: Rural nursing issues. JONA 2001; 31(6), 301-310.

3. Hamdan-Mansour A, Puskar K, Sereika S. Perceived social support, coping strategies and alcohol use among rural adolescents. Int J Ment Health Addiction. 2007; 1:53-64.

4. Makara Strudzińska M, Urbańska A. Alcohol consumption among young people from rural areas of Lublin Province. Ann Agric Environ Med. 2007; 14: 45-49.

5. Rural Healthy People 2010. The Texas A\&M University System Heath Science Center, School of Rural Public Heath, Southwest Rural Health Research Center Available at: http://www.srph.tamhsc.edu/centers/ rhp2010/litrev.htm (accessed: February 2012).
6. Miller AS. Adolescent alcohol and substance abuse in rural areas: how Teleheath can provide treatment solutions. J Addict Nurs. 2005; 3: 107-115.

7. Seo DC, Nel E, Aglej J, Ma SM. Relationship between physical activity and behavioral and perceptual correlates among Midwestern college students. J Am Coll Health 2007; 56: 187-197.

8. Owoc A, Bojar I, Sygit K, Wloch K. Health behaviors of youth from rural areas. Fam Med Prim Care Rev. 2008; 4: 1321-1324. [In Polish]

9. Antonovsky A. Can attitudes contribute to heath? Advances, J MindBody Health. 1992; 8, 4: 33-49.

10. Antonovsky A. The structure and properties of Sense of Coherence SCALE, Soc Sci Med. 1993; 36, 6: 725-733.

11. Nielsen AM, Hansson K. Associations between adolescents' health, stress and sense of coherence. Stress and Health 2007; 23,5: 331-341.

12. Posadzki P, Stockl A, Musonda P, Tsouroufli M. A mixed-method approach to sense of coherence, health behaviors, self-efficacy and optimism: Towards the operationalization of positive health attitudes. Scand J Psychol. 2010; 51: 246-252.

13. Mattila ML, Rautava P, Honkinen PL, Ojanlatva A, Jaakkola S, Aromaa M, Suominen S, Helenius H, Sillanpää M. Sense of coherence and health behaviour in adolescence. Acta Paediatr. 2011; 100(12): 1590-5.

14. Wainwright NWJ, Surtees PG, Welch AA, Nuben RN, Khaw KT, Bingham SA. Healthy lifestyle choices: could sense of coherence aid health promotion. J Epidemiol Community Health. 2007: 61; 871-876.

15. Lindmark U, Stegmayr B, Nilsson B, Lindahl B, Johansson I. Food selection associated with sense of coherence in adults. Nutr J. 2005; 28(4): 9.

16. Program Rozwoju Obszarów Wiejskich na lata 2007-2013 (2007) [Rural Areas Development Program for 2007-2013). Ministerstwo Rolnictwa i Rozwoju Wsi. Warszawa, 2007. [In Polish]

17. Juczynski Z. Narzędzia pomiarów w promocji i psychologii zdrowia. [Measurement tool in promotion and psychology of health]. Pracownia testow psychologicznych. PTP, Warszawa 2001, 119-122. [In Polish]

18. Koniarek J, Dudek B, Makowska Z. Kwestionariusz Orientacji Życiowej. Adaptacja The Sense of Coherence Questionnaire (SOC) A. Antonovsky'ego. Prz Psych. 1993; 4: 491-502. [In Polish]

19. Raport z ogólnopolskiego badania ankietowego na temat postaw wobec palenia tytoniu w 2009 roku. [National Survey Report on attitudes toward Tobacco smoking in 2009 in Poland] Państwowa Inspekcja Sanitarna. Warszawa 2009 Available at: http://www.gis.gov.pl/userfiles/ file/Raport\%202009 (accessed February 2012) [In Polish]

20. Kallioniemi M K, Simola AJK, Kymalainen HR, Vesala HT, Louhelainen JK. Stress among Finnish Farm entrepreneurs. Ann Agric Environ Med. 2008; 15: 243-249.

21. Strzelecki Z. Sytuacja demograficzna Polski. Raport 2005-2006. [Demografic situation in Poland. Report 2005-2006] Rządowa Rada Ludnościowa. Warszawa, 2006. [In Polish]

22. Saarni SI, Saarni ES, Saarni H. Quality of life, work ability, and self employment: a population survey of entrepreneurs, farmers, and salary earners. Occup Environ Med. 2008; 65:98-103.

23. Deeks A, Lombard C, Michelmore J, Teede H. The effects of gender and age on health related behaviors. BMC Public Health. 2009; Jun 30, 9: 213.

24. Haoka T, Sasahara S, Tomotsune Y, Yoshino S, Maeno T, Matsuzaki I. The effect of stress-related factors on mental health status among resident doctors in Japan. Medical Education. 2010; 8; 826-34.

25. Lam BT. Impact of perceived racial discrimination and collective selfesteem on psychological distress among Vietnamese-American college students: Sense of coherence as mediator, Am J Orthopsychiatry. 2007; 77(3): $370-376$. 